\title{
Getting a Grasp of the Grasping Involved in Understanding
}

\author{
Mikael Janvid ${ }^{1}$ (D)
}

Received: 7 July 2017 / Accepted: 9 April 2018 / Published online: 20 April 2018

(C) The Author(s) 2018

\begin{abstract}
This paper investigates some epistemic properties that distinguish understanding from knowledge. In particular, the focus is on how to spell out the notion of grasping the relationships between propositions that constitute objectual understanding: what kind of epistemic access is required for grasping to occur and to what extent is the act of grasping voluntary? A modest form of access is suggested as an answer to the first question and a largely negative answer to the second. The worry that my suggestion is too permissive in crediting subjects with understanding is addressed. The results are then finally briefly contrasted to Ernest Sosa's notion of knowing full well where one contrast precisely concerns the voluntary character of the respective epistemic states.
\end{abstract}

\section{I}

Is understanding a separate epistemic state from knowledge? Current opinion within epistemology is divided. In this paper, I focus on one part of this much-debated issue: what epistemic properties distinguish understanding from knowledge? Note, however, that this question does not presuppose separatism, i.e., the position that knowledge and understanding form distinct epistemic states. A unifier still holds that understanding constitutes a distinctive subclass of knowledge, so the question can be reformulated as what distinguishes that kind of knowledge from the other kinds.

Both separatists and unifiers typically hold that the properties comprising understanding differ from those of knowledge (or other kinds of knowledge) by being intellectually more demanding. ${ }^{1}$ My ambition in this paper is to specify what these distinguishing intellectually more demanding features of understanding are in terms of grasping. As part of this inquiry, I address and elaborate on whether these properties are non-basic, higher-order, and voluntary. To pay tribute to one of the themes of this

\footnotetext{
${ }^{1}$ See, for instance, the recent overview by Baumberger et al. 2017, 2-3, 12, 23-4.
}

Mikael Janvid

mikael.janvid@philosophy.su.se

1 Department of Philosophy, Stockholm University, Stockholm, Sweden 
conference, I shall also here in the beginning, and at the end, as well as in some remarks scattered in between, briefly raise, and comment on, the question whether these distinguishing features constitute skills.

Now regarding skills, my impression is that no consensus has yet been reached regarding their nature or epistemological significance. Nonetheless, my ambition is to conform to the ways the notion of a skill has been developed within the current discussion, but I do not aim for full coverage. Although my brief treatment will remain non-reductive, I do not take any definitive stand on the order of explication between skills and the epistemic states they supposedly form part of. ${ }^{2}$ Moreover, although doing so would perhaps more directly tie understanding to skills, I shall not be occupied with posing any operational conditions on understanding, like analyzing grasping in terms of the ability to give explanations or draw conclusions, as especially some philosophers of science attempt. ${ }^{3}$ The result of my investigation will reveal that grasping involves epistemic aspects that do not happily fit skills.

Instead, my main aim is to elucidate the epistemic properties involved in the grasping of relationships that figure essentially in many contemporary accounts of understanding. Compared to the classical tripartite analysis of knowledge as true justified belief, I shall primarily be occupied with the corresponding epistemic and doxastic constituent of understanding and leave the issue of factivity aside. ${ }^{4}$

The structure of this paper is as follows. In this section, I specify what kind of understanding I shall focus on. Section 2 brings in features, I and other epistemologists, have argued such understanding consists in, thereby throwing light on what grasping amounts to. In Section 3, I assess whether these features suggest that the act of grasping constitutes a voluntary act. Section 4 considers and responds to the objection that my account is too permissive in crediting subjects with understanding. Finally, in Section 5, my suggestions will briefly be compared to Sosa's account of knowing fully well, or aptly, and his related notion of judgment from his recent book Judgment and Agency. ${ }^{5}$ Here, the notion of a skill will briefly reappear in my discussion.

The kind of understanding where grasping plays a central role is objectual understanding. Such understanding is usually contrasted to propositional understanding. Propositional understanding, or understanding that $\mathrm{p}$, concerns understanding of particular propositions. By contrast, the objects objectual understanding varies over are wider in scope, terms like "domains" or "topics" are also employed. Precisely how to demarcate the objects in question is an intriguing task, but examples include subjects like parlamentarism, organic chemistry, nineteenth century African history, the free will problem, or Slovenian grammar. In an often quoted passage, Jonathan Kvanvig characterizes objectual understanding in the following manner

understanding requires, and knowledge does not, an internal grasping or appreciation of how various elements in a body of information are related to each other

\footnotetext{
${ }^{2}$ See Parvese 2016a. Sosa is a prominent example of the reductive approach, in, for instance, Sosa 2015. See sec. 5 below.

${ }^{3}$ For an overview, see again Baumberger et al. 2017, 13-5. I am in general suspicious towards the prospects of operational analyses of any epistemic state (a topic for another paper!).

${ }^{4}$ I discuss whether understanding is factive extensively in Janvid 2012 and Janvid 2014 where I strike a compromise.

${ }^{5}$ Sosa 2015.
} 
in terms of explanatory, logical, probabilistic, and other kinds of relations that coherentists have thought constitutive of justification. (Kvanvig 2003, 192-3, italics added)

In the next section, I shall distill several important features of understanding from this and similar passages, particularly those that bring out what grasping consists in. (In the following by "understanding" I have objectual understanding in mind.)

\section{II}

One feature that emerges from the quotation is that while knowledge can be both basic and non-basic, understanding constitutes a non-basic epistemic state with a prominent intellectual character. Understanding is not an epistemic state arrived at by any capacity in which the subject stands in direct contact with reality, like the senses or some other such basic faculty, but rather a state primarily arrived at by relating already held beliefs into a coherent body of information: to organize these beliefs precisely as relata, or infer through these relata. The subject will thus of course also be able to derive new beliefs from those she already possessed, but the classification as non-basic remains. The newly derived beliefs are based on those beliefs already held rather than formed directly based on, say, the senses. I shall return to the doxastic condition in Section 3, but note here that the non-basic character of understanding brings about a conditional character: the justification of at least some of the relata in the relationships needs to come from somewhere else.

Inference is therefore an important notion to bring in here for further elaboration. We need to dwell on this elusive operation to further spell out understanding in general and grasping in particular. ${ }^{6}$ Next, since inferring seems like something one can be skilled at, we can, in turn, relate these notions. To me, moreover, non-basic epistemic states fit better as skills. To quote Carlotta Parvese skills are

abilities that (i) are acquirable and (ii) that manifest characteristically in actions, for one is skilled at doing things and doings are actions" (Parvese 2016b, 657)

Not every perceptual ability then counts as a skill, and especially not basic cases thereof, but expert perception would, Parvese suggests. To classify non-expert basic perceptual abilities as skills would be to stretch the term, in my opinion, by suggesting voluntary control and the possibility of conscious refinement of those skills. A subject should be able to exercise a skill well or skillfully. Non-basic epistemic states also seem to have a less imposing character than basic epistemic states do, thereby suggesting voluntary control of some sort. Here, inferring seems to share these features and would thus prima facie constitute a skill. ${ }^{7}$

\footnotetext{
${ }^{6}$ I am not suggesting that inferences exhaust the relationships comprising understanding, but I do claim inferences form a substantial and significant part thereof.

${ }^{7}$ According to Zagzebski understanding is gained by learning a skill (Zagzebski 2001, 241). See note no. 16 below.

Perhaps certain inferences are constitutive of concept possession, or thought in general, and therefore not learned, but at least a significant number would still be.
} 
A further notion to explicate in the quotation from Kvanvig is the one of grasping. Here, the aforementioned feature of understanding constituting an intellectually demanding state comes to the fore. This notion can fruitfully be spelled out in terms of the familiar internalist condition that the subject must have access to the constituents of understanding. Grasping is precisely a way of capturing this internalist condition.

If you are an internalist unifier, then this internalist condition does of course not distinguish understanding from other kinds of knowledge, but note that grasping is explicated in terms of actual access rather than mere accessibility: to grasp is to access the inference in operation. It is through grasping that the actual access is obtained. Understanding thus possesses stronger internalist conditions on access than other kinds of knowledge do.

As an illustration of the stronger internalist condition posed on understanding, Linda Zagzebski writes

Understanding has internalist conditions for success, whereas knowledge does not. Even when knowledge is defined as true justified belief and justification is construed internalistically, the truth condition for knowledge makes it fundamentally a concept whose application cannot be demonstrated from the inside. Understanding, in contrast, not only has internally accessible criteria, but is a state that is constituted by a type of conscious transparency. It may be possible to know without knowing that one knows, but it is impossible to understand without understanding that one understands. (Zagzebski 2001, 246) ${ }^{8}$

Thus, understanding $\mathrm{x}$ and understanding that one understands $\mathrm{x}$ is one and the same epistemic state, according to her. The same would go for the case of grasping an inference: there is not one act of inferring and another one of grasping, but only one.

Even though Zagzebski acknowledges fallibility at the second level, ${ }^{9}$ she thus endorses a principle for understanding corresponding to the so called KK-principle for knowledge, which I in earlier writings call the UU-principle

If $\mathrm{S}$ understands $\mathrm{x}$, then $\mathrm{S}$ understands that $\mathrm{S}$ understands $\mathrm{x} .{ }^{10}$ Zagzebski thus endorses the strongest option regarding transparency: requiring that all conditions of understanding must be transparent to the subject for grasping and understanding to occur.

Let us now connect transparency to inferences specifically. At least from an externalist perspective, a subject may infer $\mathrm{p}$ from $\mathrm{q}$ without any access to the nature

\footnotetext{
${ }^{8}$ From this quotation, one can thus infer that Zagzebski does not think that understanding is factive in the straightforward way knowledge is. She writes

Truth is a thin epistemic goal, and knowledge is derivative from it, since believing the truth is a component of knowing. Understanding is a thicker goal, and its connection with truth is often indirect. (Zagzebski 2001, 245)
}

To underscore this claim, she also points to the possibility of understanding two incompatible representations of reality, ibid. 244. See Section 4 below.

9 Ibid. 246.

${ }^{10}$ The variable does not vary over propositions here, but over objects of the kind that Section 2 provides illustrations of. I have elsewhere argued that this principle is false, but for a different reason than the KKprinciple is false. See Janvid 2012 and Janvid 2014. 
of that inference; but a subject who grasps the inferential relationship that $\mathrm{p}$ stands to $\mathrm{q}$, then precisely enjoys epistemic access to the inference. If she were unable to gain any access into the inferential relationship, then her epistemic state would not be one of grasping, but simply one of basing her belief that $\mathrm{p}$ on $\mathrm{q}$.

It is undoubtedly an epistemological desideratum to account for this distinction. Should we then endorse the very demanding transparency or access Zagzebski poses?-My answer is no. Placing the internalist requirement at that end of the spectrum seems far too demanding. Just as with the case for other epistemic states, doing so leads to hardly anyone understanding anything. I am therefore going to offer a weaker condition that, nonetheless, poses stronger internalist conditions on understanding than externalists place on knowledge and therefore fulfills the aforementioned desideratum.

The access to the fulfillment of the epistemic condition is ambiguous with respect to an important distinction William Alston famously drew. Let me for the sake of clarification present and then apply his distinction between access to the ground and access to the adequacy of the ground. ${ }^{11}$ Access to the ground consists in having access to that relatum in the justificatory relation: the ground or basis of your belief. Access to the adequacy entails that access, but goes beyond by also requiring access to the adequacy of the ground qua ground. ${ }^{12}$

An externalist omits both as conditions on knowledge, but I suggest that understanding requires the former kind of access, i.e., access to the ground, which in the case of understanding amounts to having access to the epistemic relation the relata stand to one another. It is precisely this relation that the subject grasps when she understands. Posing the very strong internalist conditions on understanding as Zagzebski does could then naturally be interpreted as demanding the stronger form of access: having access to the adequacy of the inference in question. By gaining access to the adequacy of the relationships comprising the object of understanding, the subject would understand that she understands that object.

Let me illustrate the different forms of access with a case of simple enumerative induction. From a number of premises where the subject observes that an object a is F, the subject infers that all objects a are F.

Now, (i) to just base the belief in the conclusion on the premises, i.e., the observations, without having any access to the inference in question, would still count the subject as being justified in believing the conclusion that all a:s are $F$ from an externalist perspective, but not as having gained any understanding. In this case, the subject has not grasped the inferential relationship the premises stands to the conclusion, but she may still be justified in believing the conclusion of the inference.

Next, we apply Alston's distinction to generate (ii) access to the inference by which the subject reaches the conclusion from the premises, which is what I am now suggesting grasping, as a constituent of understanding, consists in, and (iii) in addition, to have access to the adequacy of the inference by which the subject reaches the conclusion from the premises. (iii) constitutes an excessively strong requirement, even

\footnotetext{
${ }^{11}$ In Alston 1989.

${ }^{12}$ In Alston's case adequacy consists in the ground being sufficiently truth conducive with respect to the belief. The ground constitutes a reliable indicator of the truth of the belief (see Janvid 2017). I agree.
} 
for understanding, that few ever fulfill. Moreover, in the case of basic inferences, no one could ever fulfill this condition. ${ }^{13}$

In the case of (ii), the subject need not possess the concept of induction, but she does need to access having based her conclusion that all a:s are $\mathrm{F}$ on her having noted that all a:s observed so far are F. My conjuncture is thus that both (ii) and (iii) provide cases of understanding, while (i) does not. My middle ground proposal is that (ii) suffices for grasping and understanding even though the strongest kind of internalist access is not reached. Even without the strongest form of access, (ii) still captures the crucial difference between being justified in believing a conclusion $p$ versus being justified in believing p qua conclusion. (ii) is not necessarily meant to convey that the subject necessarily grasped how her belief in the conclusion was initially formed, it may instead at a later point in time "merely" capture how her belief is maintained.

\section{III}

Let us now turn to the doxastic condition where most epistemologists hold that understanding entails belief just like knowledge does. The state of understanding is stored as beliefs in the subject. The same would go for grasping: although new beliefs are not necessarily formed, already existing beliefs become more entrenched and stable by the grasping of the relationships they stand to one another.

I beg to differ. In virtue of its conditional, non-basic character, an important difference between understanding and knowledge precisely consists in that a subject may possess understanding without having any beliefs about the relata comprising the object of understanding. The required grasping of relationships can occur without the subject believing in any of the relata, or for that matter, even if the subject has false beliefs regarding them. ${ }^{14}$ The relata merely need to be comprehended, but not believed.

One way to illustrate this point is that a subject may grasp how incompatible propositions are derived from different theories and, as a result, refrain from believing in any of the alternatives. Understanding thus lacks a no defeater condition. More precisely, understanding is compatible with overriding defeaters to any of the relata of the relationships, which in turn comprise the object of understanding. ${ }^{15}$ However, the subject needs to believe in the conditional that captures the inferential relationships that hold between the relata. It is those the subject grasps. (See Section 5 below.)

Here, we thus seem to come across an aspect in which understanding supposedly fits skills in that the subject precisely can abstain from belief. Such abstinence can occur without endorsing doxastic voluntarism since it is not in the possession of the beliefs in the relata the epistemic state resides. The ability of grasping relationships would also be something you could acquire, at least more complicated ones, as well as become more skilled at.

\footnotetext{
${ }_{13}$ By a basic inference, I mean an inference not based on any other inferences.

${ }^{14}$ I give several examples in Janvid 2012 and Janvid 2014. By false belief I mean that the subject may believe in a false proposition (relatum) without loss of understanding. This is not to deny of course that the overall epistemic standing of the subject is negatively affected by having a false belief, only that the state of understanding need not be.

${ }^{15}$ I give further examples in Janvid 2012 and Janvid 2014. To use the recent terminology of Sosa 2015, the subject need not affirm any of the relata. See below in Section 5.
} 
However, the grasping of the relationships is not a voluntary act. It is no coincidence that the episode is typically characterized as one of "seeing," thereby suggesting that grasping, like seeing with your eyes, is not voluntary. Once you notice the relationship, it phenomenologically strikes you. The subject is fallible in this regard, both when it comes to whether it really is in virtue of the grasped relationship she believes in the conclusion (insofar as she does) and whether the relationship is a genuinely epistemic one. Importantly, on my account the relationships grasped are subject to externalist conditions in that, first, whether the relation really obtains between premises and conclusion is an objective fact about which the subject may be mistaken no matter how reasonable the connection seems to her; and second, whether the relation is genuinely epistemic is likewise an objective fact about which the subject may be mistaken, no matter how strongly she believes it is. ${ }^{16}$ So not just any relation qualifies as epistemic, no matter how well the subject grasps the relation psychologically.

The subject can thus resist believing in the conclusion (and/or the premises for that matter), but the grasping of the relationship holding between the premises and the conclusion is not likewise a voluntary act. Note here that the ability to refrain from believing the conclusion does not depend on lack of belief in the relata constituting the premises. Even if the subject does believe in the premises, she might still not believe in the conclusions drawn from them. The subject might, as I noted before, for instance, arrive at incompatible conclusions drawn from different premises and inferences she also believes in. ${ }^{17}$

A subject thus cannot choose to grasp, respectively refrain from grasping, an inference. A final point in this regard: a subject who grasps the inference by which she arrives at the belief that all a:s are F is intellectually more sophisticated than someone who remains at level (i). If it is such intellectual sophistication that the phrase "reaching a higher epistemic level" signifies, then I have no quarrel with that classification. To me, however, a higher epistemic level suggests a stronger epistemic position, i.e., that the justification is stronger in (ii) than in (i) and thereof no guarantee is obtained. (iii) would indeed be so (see next section), but is precisely therefore a largely elusive state.

Thus, by classifying (ii) as understanding I do not thereby intend to improve on the (externalist) justification already present in (i). By gaining understanding, the subject does not enhance the justification already present in (i). ${ }^{18}$ On the contrary, the epistemic

\footnotetext{
${ }^{16}$ It is in virtue of these externalist conditions that understanding qualifies as an epistemic state on my account despite lacking straightforward factivity. See Janvid 2014.

Note that I do not mean to deny that there can be a number of skills the subject possesses which may enable her to grasp relationships constitutive of understanding, nor for that matter that the grasping of such relationships may in turn enable the subject to acquire further skills. However, just as in other cases within epistemology where enabling conditions figure, such enabling conditions do not form part of the epistemic nature of grasping. Moreover, what those enabling skills more precisely are, as well as their precise nature and role, are empirical questions. Thanks to an anonymous referee for prompting this clarification.

${ }^{17}$ Does not the affinity with seeing tell against grasping and understanding being non-basic? Rationalists like BonJour certainly regard intellectual intuition as a basic faculty. Here is not the place to plunge into details, but the important point is that intellectual intuition can provide both basic and non-basic justification depending on what the grasped beliefs themselves are. Since understanding consists in the grasping of relationships between the relata unlike, say, grasping axioms, its non-basic character is not affected. Kurt Sylvan raised this question at the Bled Conference.

${ }^{18}$ As Sosa seems to suggest in Sosa 2009, part II. See also Section 5 below.
} 
state of understanding essentially depends on that justification. As non-basic, understanding does not constitute, or improve on, the justification of basic inferences.

\section{IV}

One might wonder whether my moderately internalist suggestion is too permissive in line with a serious objection raised against externalism. ${ }^{19}$ The problem for externalism is that, as long as there is a reliable connection between two beliefs, a subject believing in one of the beliefs is justified in believing the other belief, even in cases where she clearly ought not to be so. To take an example from Paul Boghossian: from a belief in some simple arithmetic truth, a subject would, through entailment, be justified in believing Fermat's last theorem.

Does adding access to the ground enable externalism to deny that the subject has grasped the inference in such a case and thus (rightly) lacks understanding? If we add condition (ii) to the case at hand, then the subject would be aware that she bases her belief in Fermat's last theorem on the simple arithmetic truth, say $2+2=4$. Ideally, adding this condition should underpin the intuitive negative classification. The desired outcome is that this subject is neither justified in her belief in that theorem as conclusion of that inference, nor does she thereby understand that advanced part of arithmetic. The subject does not grasp any epistemically significant relation between these propositions.

In order to address this issue properly, I need to spell out my suggestion further. But before I do that, I would like to discard some red herrings, concerning the challenge as such, that might lead us astray. First of all, both the propositions believed are necessary. Such propositions create well known obstacles for externalism, but the objection should be independent of the modal status of the involved propositions. The epistemic promiscuity occurs for relations between contingent propositions as well.

Second, related to the first point, the first proposition entails the second one. (The second of course conversely entails the first proposition as well since the propositions precisely are necessary.) The entailment relation also gives rise to familiar problems within epistemology. For instance, subjects seem to be rationally committed to believing all entailed beliefs of the ones they hold. The standard move is to restrict them to known entailments. Baron Reed aptly remarks (in a different context) "entailment is not in itself an epistemic relation". ${ }^{20}$ For internalism, the mere presence of a relation between two relata does not suffice for a subject being justified; an additional access to that relation is also required. Since externalism precisely omits access conditions on justification where internalists pose them, maybe we have here come across a problem for externalism specifically. The challenge for externalism, then, consists in how to likewise internalize the relevant relation in an epistemically appropriate fashion without posing any access condition. The problem arises for any "reliably truth-preserving" relation one relatum stands to the other. Here, the basing relation might come to the

\footnotetext{
${ }^{19}$ See Boghossian 2003 and Boghossian 2014. The objection is directed against a position he calls simple inferential externalism, but it is clear from his discussion that externalism in general is supposed to be affected. ${ }^{20}$ Reed 2012, 586.
} 
rescue with respect to internalization, but adding that requirement does not help in the case at hand for the two first reasons already stated.

Let me note on the side that I am unsure whether adding this epistemic constraint is sufficient for understanding in cases of entailment. Boghossian's example contains two arithmetical propositions belonging to the same object of understanding. However, since any necessary proposition stands in a relation of reciprocal entailment to any other necessary proposition, a haphazard object can be conjoined out of any disparate necessary propositions from different domains. Accordingly, as long as the subject knows their general modal status, i.e. that they are necessary, the subject seems to possess understanding of this strange object. ${ }^{21}$

Third and last, our intuitions may differ depending on whether the inference in question is basic or not. In the case of the proof of Fermat's last theorem, more specific and highly advanced mathematical beliefs and lemmas are needed to get the proof off the ground and many intermediary steps must be taken in order to arrive at Fermat's last theorem; for instance, apparently along the way one needs to prove something called the Taniyama-Shimura conjecture which says that every elliptical equation can be correlated with a modular form. ${ }^{22}$ So the inference arriving at Fermat's last theorem is not basic, and accordingly, an externalist could plausibly claim that a subject needs to base her belief in the theorem on these intermediate steps in order to possess understanding.

The externalist might thus pose a dilemma to internalism: the inference is either basic or not. Now as we have just seen, externalism may escape permissiveness with respect to non-basic inferences. What about basic inferences then? Here, internalism is at least as worst off as externalism for well-known reasons. Neither position can offer what internalism requires for justification; the subject is instead caught in a regress or a circle. $^{23}$ The externalist thinks that the lesson to learn is that at some point we must go external and basic inferences seem a good point to do so.

With these provisos made, is the limited access I propose, which omits access to the adequacy of the inference, sufficient in meeting the charge of granting understanding too promiscuously? I suggest that emphasizing that the stronger form of access in (iii) requires access to the objective adequacy provides the key for giving a positive answer to the question. In (ii) the subject does lack access to the objective adequacy, but if she herself does not think that the conclusion follows from the premises, then how she arrives at the conclusion from the premises will seem like a mystery to her, reminiscent of how Laurence Bonjour depicts his famous reliable clairvoyants. ${ }^{24}$ This phenomenological character of the inference does not of course amount to the inference thereby being objectively adequate. Nonetheless, how the subject could conclude that Fermat's last theorem holds because $2+2=4$ would seem obscure to her (and rightly so). Rather

\footnotetext{
${ }^{21}$ Regarding the useful term general modal status, see Casullo 2003, 91-3, as well as several papers in Casullo 2012.

22 Boghossian 2003, 244. To prove a theorem could naturally be subsumed under iii.

23 As Boghossian also notes in Boghossian 2003, 229-30.

${ }^{24}$ BonJour 1980 and BonJour and Sosa 2003, Ch. 2. (In that thought experiment clairvoyance should be classified as a basic faculty.) Grimm employs the term "opaque" in a similar context in Grimm 2017, 220. Although Grimm does not draw the distinction between access to the ground and access to the adequacy of the grounds, he rejects strong transparency citing psychological studies of infant and animal cognition as support that they possess the dependency relations he believes understanding consists in.
} 
than treating the conclusion as the result of an inference, the "conclusion," in so far as the subject would feel inclined to believe the first proposition based on the second proposition, would rather appear as the result of compulsion. Both scenarios would be compelling for sure, but in very different ways for the subject. I therefore believe that my moderate internalist suggestion gives the right verdict for the right reason and thus escapes the charge of permissiveness. ${ }^{25}$

\section{$5 \mathrm{~V}$}

Having already mentioned Sosa's account from his latest book, it may be illuminating finally to compare and contrast the results gained so far regarding understanding with his SSS-structure for epistemic competences together with his recently developed notion of knowing full well whereby he replaces reflective knowledge. ${ }^{26}$

Sosa analyzes competences in terms of what he dubs the SSS-structure. The SSSstructure is spelled out as Seat, Shape, and Situation where skill depicts the innermost basis - the seat of the competence. ${ }^{27}$ He holds that all epistemic states are constituted by competences and that all competences display this structure. Sosa's employment is clearly more general than Parvese's. Sosa here distinguishes between functional and intentional beliefs. Both kinds of beliefs aim (constitutively) for truth and can therefore be classified as actions. Whilst the former aims so "through psychological or biological teleology", the latter can do so consciously. ${ }^{28}$ Despite this distinction, Sosa in my mind stretches the notion by letting skills form part of any epistemic state/competence. I remain unpersuaded: skills, as actions, only fit the intentional side of the divide and actions are few and far between in epistemology. ${ }^{29}$

One aim for Sosa in the book is to develop his notion of knowing full well or fully apt and to stress the importance of that epistemic state. ${ }^{30}$ When a subject knows fully well or aptly, she aptly attains aptness of affirmation, which in his terminology amounts to a judgment

\footnotetext{
${ }^{25}$ Note here that the ground requirement precludes the development of a coherentist scenario where the subject entertains weird background beliefs making the inference justified solely by forming part of a coherent system of beliefs.

What about a subject who does not find the inference mysterious?-Then too many other beliefs and relationships would be unjustified for her to possess objectual understanding about the subject matter.

${ }^{26}$ Kvanvig regards Sosa's account of reflective knowledge as close to his own account of understanding, once again stressing coherence, in Kvanvig 2003, 206.

${ }^{27}$ Sosa 2015, 26-30, 95-7.

${ }^{28}$ ibid., 51. Sosa also distinguishes between functional knowledge and judgmental knowledge where the latter precisely constitutes the epistemologically relevant kind of a consciously intentional act (66-7).

${ }^{29}$ Unsurprisingly given my account of the involuntary account of grasping in Section 4, I am instead in large agreement with, for instance, Kornblith's criticism of epistemic agency in Kornblith 2012, Sec. 3.3-3.7 and Kornblith 2017. Let me also take the opportunity to point out that I am fully aware of not presenting any systematic refutation of Sosa's intriguing views in this short section nor do I take any stand on where the burden of proof lies in presenting the most promising account of belief, intention or action. My aim is rather to "compare and contrast" just as I state in the first paragraph of the present section. Thanks to an anonymous reviewer for prompting this proviso.

${ }^{30}$ Ibid, 51, 53, 74-7.
} 
Once the affirmation also aims to get it right aptly, then it ascends epistemically to the level of judgment. An apt judgment is hence a fully apt affirmation, one that aims for aptness in alethic affirmation, and aptly attains that objective. (Ibid, 93. $)^{31}$

Does my suggestion then classify understanding as fully apt?-No, it does not. Let me point to some important contrasting features. (1) As we have seen, I suggest that access to adequacy is not required for understanding, so the subject need not have any objective epistemic access into the adequacy of her epistemic state. The subject need not, then aptly attain apt understanding. Moreover, (2) unlike the state of knowing full well, no epistemic enhancement occurs in gaining understanding in that the original justification of the relata or the relationships themselves becomes stronger (which I hold would be required). ${ }^{32}$ (3) No increased confidence need to occur in the subject as she gains understanding and, moreover, if such an increase does occur, the epistemic position is not solely thereby strengthened. ${ }^{33}$ (4) As we have seen, the grasping of the relationships is not a voluntary conscious act as judgments are. ${ }^{34}$ Grasping thus belongs to the functional side of the divide Sosa distinguishes.

(5) Finally, no second order epistemic state is necessarily involved in understanding and, in particular, no second order guiding of the first order necessarily takes place in reaching understanding. ${ }^{35}$ In fact, even less so in one crucial aspect: since the relata need not be beliefs, the belief about the relationships they stand to each other must not be second order for the sake of being a belief about a belief. So no second order is necessarily involved unless the claim is that the internalist condition of awareness always requires epistemic states to be raised to a higher level. In that case, however, understanding would not stand apart in this respect from any other epistemic state falling under the internalist condition.

\footnotetext{
$\overline{{ }^{31} \text { See also ibid., 80, } 124 \text { and } 150}$ ). In Sosa 2007 he says
}

[p]erformances with an aim, in any case, admit assessment in respect of our three attainments: accuracy: reaching the aim; adroitnesss: manifesting skill or competence; and aptness: reaching the aim through the adroitness manifest (23).

\footnotetext{
${ }^{32}$ See reference in note no. 18 above.

${ }^{33}$ Sosa 2015, 89-91.

34 Ibid, 55, 209-10.

35 Ibid, 54, 73-6, 82-8, 165. I find Sosa's discussion of second order states puzzling. Second order mental states are states about other mental states, so, typically, a second order belief is a belief about a belief. When investigating his central notion of judgment, Sosa claims that
}

\begin{abstract}
his judgment will be apt only if he aptly attains this aim: that of affirming aptly. And this will happen only if he is guided to the aptness of his affirmation [...] by his second-order awareness that if he then affirmed [...] he would (likely enough) be right. (79, see also the subsequent page.)
\end{abstract}

An attached note points out that the awareness does not need to be conscious. It is far from clear to me that this is indeed the only way to account for this phenomenon, even if it is so relevant as Sosa holds. While he seems to desire to bring in the second order level, my inclination would be to avoid that unless one must, by, for instance, instead construing the competence manifested as fully apt judgment as being apt in forming (or sustaining) apt beliefs. (Sosa here offers a partial disclaimer on p. 84 and on pp. 108-9.) 
What Sosa shows at most is that if a subject has a full blown intention and makes a conscious decision to affirm, deny or suspend judgment, then the resulting state is second order, ${ }^{36}$ but the subject can grasp relationships without undergoing any of these second order mental processes. Note here that neither the non-basic, nor the relational character of understanding, entail a second order status; nor does the more demanding condition of access to the adequacy - that is just another kind of access into the epistemic properties of the epistemic standing in question. Understanding and knowing full well thus come apart. For my purpose of investigating understanding, Sosa's account offers at best a case of a sufficient rather than a necessary condition and, often, superfluous hyper-intellectualization.

To sum up, we have gained headway into the elusive nature of grasping as a constituent of understanding by, for instance, employing Alston's useful distinction between access to the ground and access to the adequacy of the ground. However, although grasping shares some features with skills in a narrow sense, we have noted that other features do not fit well, so subsuming understanding under skills does not seem a fruitful or illuminating endeavor. In particular, unlike grasping an object with your hands, mental grasping is not a voluntary act.

Acknowledgments I am grateful to the participants in the XXVth Bled Philosophical Conference "Epistemic Virtues and Epistemic Skills" and an anonymous referee of this journal for helpful comments on earlier versions of this paper.

Open Access This article is distributed under the terms of the Creative Commons Attribution 4.0 International License (http://creativecommons.org/licenses/by/4.0/), which permits unrestricted use, distribution, and reproduction in any medium, provided you give appropriate credit to the original author(s) and the source, provide a link to the Creative Commons license, and indicate if changes were made.

\section{References}

Alston, W. 1989. “An Internalist Externalism” reprinted in Epistemic Justification. Essays in the Theory of Knowledge. Ithaca: Cornell University Press, 227-245.

Baumberger, C., Beisbart, C., \& Brun, G. (2017). What is Understanding? An overview of recent debates in epistemology and philosophy of science. In S. Grimm, C. Baumberger, \& S. Ammon (Eds.), Explaining Understanding. New Perspectives from Epistemology and Philosophy of Science (pp. 1-34). New York: Routledge.

Boghossian, P. (2003). Blind reasoning I. The Aristotelian Society, Supplement, 77, 225-248.

Boghossian, P. (2014). What is inference? Philosophical Studies, 169, 1-18.

BonJour, L. (1980). Externalist theories of empirical knowledge. Midwest Studies in Philosophy, 5, 53-73.

BonJour, L. \& Sosa, E. 2003. Epistemic justification: internalism vs externalism, foundations vs. virtues. Blackwell.

Casullo, A. (2003). A priori justification. Oxford: Oxford University Press.

Casullo, A. (2012). Essays on a priori knowledge and justification. Oxford: Oxford University Press.

\footnotetext{
${ }^{36}$ Ibid, 109-10. Sosa thinks that suspension clearly shows the "insufficiency" of staying at the first order level, since in suspension "one double-omits intentionally by neither affirming nor denying" even necessarily (110) so. Once again, I acknowledge that this can happen, but I doubt it must happen. Sosa argues that "since the other two choices <promotion, opposition> are presumably on the same order as neutrality, since they too might properly result from such deliberation, they too are hence plausibly on the second order" (ibid.) I would rather turner the argument on its head.
} 
Grimm, S. (2017). Understanding and transparency. In S. Grimm, C. Baumberger, \& S. Ammon (Eds.), Explaining Understanding. New Perspectives from Epistemology and Philosophy of Science (pp. 212229). New York: Routledge.

Janvid, M. (2012) Knowledge versus Understanding: The Cost of Avoiding Gettier. Acta Analytica 27 (2): $183-197$.

Janvid, M. (2014) Understanding Understanding: An Epistemological Investigation. Philosophia 42 (4):971985.

Janvid, M. (2017) Defeater Goes External. Philosophia 45 (2):701-715.

Kornblith, H. (2012). On reflection. Oxford: Oxford University Press.

Kornblith, H. (2017). How central are judgment and agency in epistemology? Philosophical Studies, 174, 2585-2597.

Kvanvig, J. (2003). The value of knowledge and the pursuit of understanding. Cambridge: Cambridge University Press.

Parvese, C. (2016a). Skill in epistemology I: skill and knowledge. Philosophy Compass, 11, 642-649.

Parvese, C. (2016b). Skill in epistemology II: skill and know how. Philosophy Compass, 11, 650-660.

Reed, B. (2012). Fallibilism. Philosophy Compass, 7/9, 585-596.

Sosa, E. (2007). A virtue epistemology. Apt belief and reflective knowledge, volume 1. Oxford: Oxford University Press.

Sosa, E. (2009). Reflective knowledge. Apt belief and reflective knowledge, Vol. II. Oxford: Oxford University Press.

Sosa, E. (2015). Judgment and agency. Oxford: Oxford University Press.

Zagzebski, L. (2001). Recovering understanding. In M. Steup (Ed.), Knowledge, truth and duty (pp. 235-251). New York: Oxford University Press. 